\title{
O que a imprensa registrou
}

\section{JORNAL DO BRASIL}

\section{EDITORIAL}

"Começa a reforma administrativa, não por vias de impacto e sim por meio de diretrizes divididas em etapas, algumas das quais à espera de definiçāo. Optou o Presidente da República, ao assinar oito decretos iniciais, pela execução gradual das mudanças básicas que propoe fazer na máquina estatal. Abriu mão o Governo de orcamentos promocionais que quase sempre criam expectativas maiores que na realidade sảo. Terá perdido em repercussão; porém, terá ganho em objetividade. $\dot{\mathrm{E}}$ mais importante, hoje, para o Pais, saber que a reforma administrativa resulta de um compromisso pessoal e de um conceito politico do presidente Sarney do que vê-la sujeita às flutuaçoes do momento eleitoral. O que o Pais quer é uma reforma administrativa para valer". ("Reforma Gradual", segundafeira, 15/9/86)

\section{(iA/ITIA MLRCANTIL}

\section{EDITORIAL:}

"A reforma administrativa, digase de passagem, deve ser entendida como uma forma mais eficaz de controle pelo Governo dos gastos de custeio de sua máquina. Noticiouse, nos últimos dias, que, em face de denúncias de que órgãos da administraça direta vinham contratando pessoal, em desobediência expressa às determinaçỏes em vigor, o Presidente da Repúblicà exigiu explicaçoes dos ministérios envolvidos. Fala-se que năo teria havido rcalmente um aumento de quadros, mas remanejamento de funcionários. A impressão que se tem $\dot{e}$ de que a cúpula do Governo nảo tem instrumentos para impor um controle como o que as circunstâncias tornam inadiável. A expectativa é de que a reforma administrativa possa efetivamente dar racionalidade à máquina do Governo e que ela possa ser operada com mais eficiência e menos desperdicio. O que a Nação espera é que a reforma tenha o valor de um exemplo".

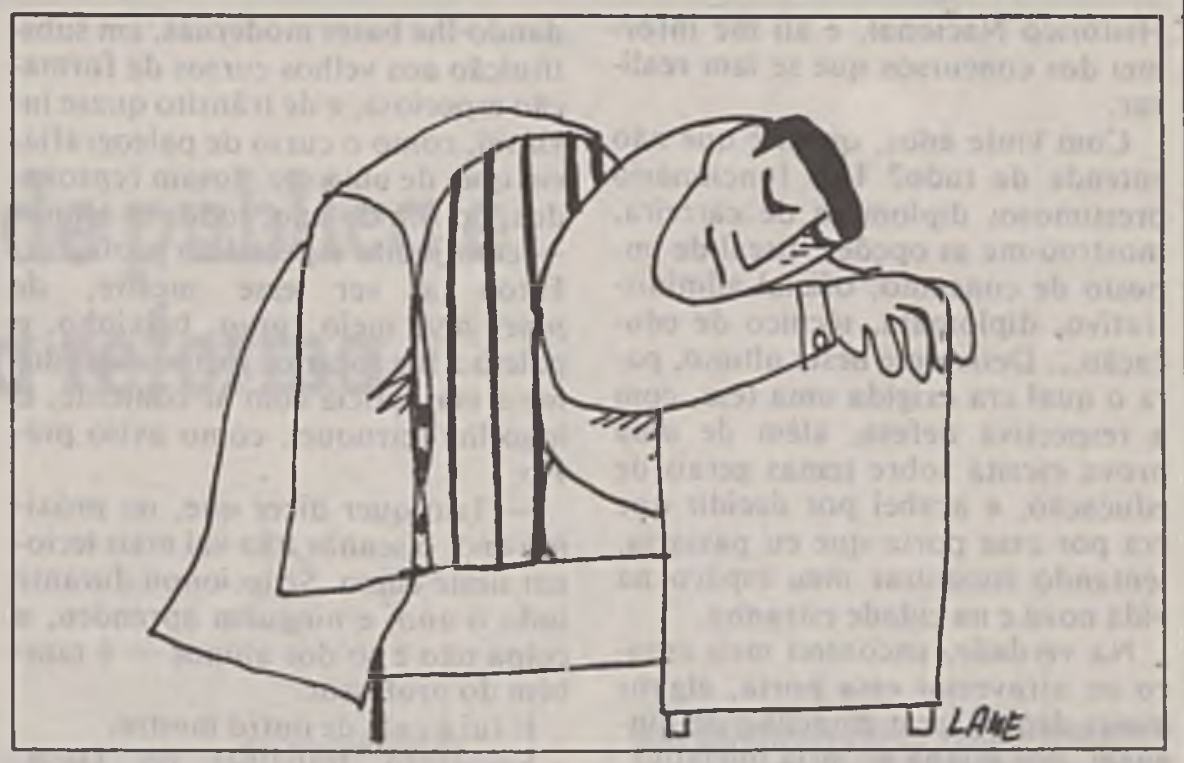

TORNAT DO BRASL

\section{A reforma administrativa}

("Oportunidade para demonstrar os propósitos de austeridade", quinta-feira, 28/8/86).

\section{CORREIO BRAZILIENSE}

\section{EDITORIAL:}

"Ao assinar oito decretos-leis para lastrear o advento da Reforma Administrativa, o presidente José Sarney deu o primeiro passo no rumo da modernização da burocracia estatal brasileira, cuja defasagem funcional, i térnica e politica responde pela ineficácia da máquina governamental da União. Os instrumentos legais agora editados não abarcam a generalidade dos problemas diagnosticados, há tempos, no âmbito do Serviço Público Federal e das agências paralelas criadas para dinamizar a aça oficial, entre as quais avultam as empresas estatais e as fundaçōes estipendiadas pelo Tesouro. O importante é estabelecer uma nova politica administrativa capaz de fulminar os agentes que respondem pela histórica ineficácia do Estado brasileiro e pelos gargalos que estrangulam as açðes governamentais".

("Reforma Administrativa", sexta-feira, 5/9/86).
Josué Montello

\section{ARTIGO:}

"Numa charge"de J. Carlos, publicada na Careta há muitos anos, um grave funcionário público, desses que ainda usavam paletó de lustrina na repartiçao, admoestava assim um de seus auxiliares, no tom severo que as circunstâncias exigiam:

- O senhor, além de dormir na repartição, ronca tão alto, que acorda o nosso diretor, que Irabalha aqui ao lado.

Por esse tempo, como se vê, as repartiçōes públicas ainda ofereciam oportúnidade para o iazer e o sono. Depois, tudo se complicou. Cresceram os setviços, acumularam-se os processos, aumentou consideravelmente o número de funcionários, de modo que a máquina burocrática, imensa, derrancada, complexa, facilitou o ingresso de novos servidores pelo regime do empenho político, ou das boas relações providenciais.

Ora, eu tive a sorte de chegar ao Rio de Janeiro, vindo de minha provincia natal, na época em que o presidente Getúlio Vargas instituiu, como regra geral, o sistema do mérito, para a ampliação natural dos quadros administrativos.

Lembro-me bem de que, alertado por uma noticia publicada no Correio da Manhã, fui à pequena sala que o Dasp ocupava na Ponta do Calabouço, no fundo do Museu 


\section{O que a imprensa registrou}

Histórico Nacional, e ali me informei dos concursos que se iam realizar.

Com vinte anos, quem é que não entende de tudo? Um funcionârio prestimoso, diplomata de carreira, mostrou-me as opções: fiscal de imposto de consumo, of icial administrativo, diplomata, técnico de educação... Detive-me neste último, para o qual era exigida uma tese, com a respectiva defesa, além de uma prova escrita sobre temas gerais de educação, e acabei por decidir que era por essa porta que eu passaria, tentando encontrar meu espaço na vida nova e na cidade estranha.

$\mathrm{Na}$ verdade, encontrei meu espaco ao atravessar essa porta, alguns meses depois, sem empenho de ninguém, por minha prọpria inicialiva, após o concurso e a classificação respectiva.

Não tardei a ser chamado pelo próprio Dasp, e ali trabalhei, como técnico de educação, nos seus cursos de administração, ao tempo cm que os dirigia meu saudoso amigo e colega Jubé Júnior.

Tive a meu cargo, por esse tempo, a coordenação dos professores dos mesmos cursos, e para eles fui buscar, com a responsabilidade de lecionar Direito Administrativo, o professor Djacir Meneses, como também recrutei, para o (urso de Português Prático, o professor Júlio Nogueira.

Houve um tempo em que, na Divisão de Aperfeç̧oamento, a que cu pertencia, so trabalhavam funcionarios e técnicos recrutados cm concurso. Eu proprio tive de dar um Curso de Organizacialo e Administracão de Bibliolecas, para substituir uma professora americana, Margaret Bates, que, por motivos pessoais, regressou as pressas aos Estados Unidos, deixando $\mathrm{cm}$ meio o curso que vinha lecionando.

o Curso de Organizaça e Administração de Bibliotecas, que figura na minha bibliografia, adveio dai, com as sumulas de minhas aulas. Pude contribuir, desse modo, para a formação de algumas lurmas de técnicos, que depois assumiram posicão de relevo na carreira e que trabalharam comigo, ao tempo $\mathrm{cm}$ que dirigi a Biblioteca Nacional.

$\mathrm{Na}$ linha dessa preparação técnica do servidor público, reorganizei os cursos da Biblioteca Nacional, dando-lhe bases modernas. em substituição aos velhos cursos de formacão especiosa, e de trânsito quase inviável, como o curso de paleografia, em que, de uma vez, foram reprovados, no fim do ano, todos os alunos - com júbilo especial do professor. Estou a ver esse mestre, de pince-nez, meio curvo, baixinho, o paletó a the roçar os joelhos, dandome a má notícia com ar contente. E logo the retruquei, como aviso prévio:

- Isso quer dizer que, no próximo ano, o senhor não vai mais lecionar neste curso. Se lecionou durante todo o ano, e ninguém aprendeu, a culpa não é só dos alunos - é também do professor.

E fui à cata de outro mestre.

Enquanto trabalhei no Dasp, dirigia-o, como seu grande comandante, o meu velho amigo Dr. Luis Simões Lopes, benemérito do servico público, grande figura humana, a quem devemos o ter transferido para al lundação (ietúlio Vargas o sentido da atualização técnica com que deu vida ao Departamento Administrativo do Serviço Público.

De ver cm quando, ao encontrarme com Benedito Silva e Cleanto de Paiva L citč, um na Fundação Getúlio Vargass, outro na Presidência do IBE:C, temos de reprimir o saudosismo do Datsp de outrora, porquanto nos sentimos associados à instituifilo e a sua lase áurea.

Depois... () Dasp, conquanto continuasse a prestar relevantes serviços, perdeu a força normativa em que se inspirara, sem dispor mais de meios para conter a confusa que se veio criando pelo tempo adiante, coll institutos, autarquias, órgãos paralclos, cada qual mais poderoso que o outro, ao arrepio da disciplina de ordem geral.

Por isso, ao ver que se inicia a Reforma Administrativa, confiada a Aluizio Alves no atual Governo, tenho de levantar-me da cadeira e bater palmas, sabendo que, sem essa reforma, o Presidente da República, com todos os seus poderes, nada mais seria do que administrador do caos, na confusão do serviço público federal.

A Escola Nacional de Administração, agora criada, reata a boa tradição dos Cursos do Dasp. Com esta diferença, segundo imagino: estes, mais próximos dos modelos americanos; aquela, inspirada na experiência francesa. Fugindo certamente aos excessos burocráticos, próprios de nossa condição latina, muito inclinada ao gosto do papel e ao rito oficial, já profligado pelo riso de Courteline em Monsieur Badim e em Messieurs les Rondsdecuir e a que pende também o nosso temperamento, se não the abrandamos em tempo o gosto da eloqüência e da representação oficial.

A reforma encontrará resistências, principalmente da parte daqueles que conquistaram privilégios, à revelia das normas que o Dasp implantou nas suas origens, para a política de recrutamento de pessoal. E não é apenas necessária- é indispensável como fundamento de uma nova ordem construtiva para o País. Voltada para o futuro.

Com as normas vigentes, Machado de Assis e Artur Azevedo não teriam chegado a chefes de seção, no ponto mais alto de suas carreiras burocráticas, simplesmente porque não dispunham de um título universitário, que hoje se exige - se estou bem informado - para a promoção e a melhoria de vencimentos. Título que por vezes nada tem a ver com o cargo exercido, mas que serve para o empurrão providencial do fim de carreira.

A reforma, ao que me consta, ajustará o título à função, para que a conquista do canudo, ou do diploma, faça sentido com o exercicio do cargo. Dai a necessidade da Escola Nacional de Administração, com o espirito de aprimoramento que inspirou o Dasp ao tempo de Luis Simōes Lopes. Vai dar excelentes resultados, sobretudo no que concerne à formação de uma elite administrativa.

Convém não perder de vista a preservação do Instituto Rio Branco, que tão relevantes serviços tem prestado ao Pais na formação da elite diplomática de que nos orgulhamos. Conheço-lhe os valores e a disciplina, sci assim o que essa elite significa para o Pais.

Convém lembrar que Portugal alicerçou a unidade de seu império, depois da epopéia das descobertas, graças sobretudo à unidade das veIhas Ordenações em que se baseou para governá-lo. A unidade do Brasil é, em grande parte, o resultado dessa disciplina administrativa." 